\title{
Effect of SiC Nano powder on Multiaxial Woven and Chopped Randomly Oriented Flax/Sisal Fiber Reinforced composites
}

\author{
Ganesh R. Kalagi ${ }^{1}$, Rajashekar Patil ${ }^{1}$, Sunil Kumar Shetty ${ }^{2}$ and Madhukara Nayak ${ }^{3}$ \\ ${ }^{1}$ REVA University Bengaluru, Karnataka, India \\ ${ }^{2}$ NMAMIT, Nitte, Karnataka, India \\ ${ }^{3}$ SMVITM, Bantakal, Karnataka, India
}

\begin{abstract}
A study has been carried out to investigate effect of SiC Nano powder on tensile and impact properties of Multiaxial layers of Flax and Sisal fiber reinforced composites and randomly oriented chopped Flax and Sisal fiber reinforced composites. It has been observed that tensile strength and impact strength were improved using $6 \%$ of $\mathrm{SiC}$ Nanopowder into Multiaxial layer $\left(+45^{\circ} /-45^{\circ}, 0^{\circ} / 90^{\circ}\right)$ of Flax and Sisal where as randomly oriented chopped Flax and Sisal fiber reinforced composites are improved in its stiffnes for the same composition of fiber, epoxy and SiC Nano powder. SEM Analysis are done to analyse the distribution of $\mathrm{SiC}$ in both Multiaxial layers of Flax and Sisal fiber reinforced composites and randomly oriented chopped Flax and Sisal fiber reinforced composites.
\end{abstract}

\section{Introduction}

Natural fiber reinforced composites are alternative materials for many applications such as small wind turbine blades, automobile applications, and aerospace applications [1]. Natural fibers shows superior properties such as tensile, flexural and impact than glass fiber [2]. Low cost, light weight, easy fabrication, ecofriendly, low manufacturing cost are the advantages of natural fibers $[3,4]$. But high moisture absorption is major drawback of natural fiber [7]. European cars are already using Natural fiber reinforced composites due to more favorable economic, environmental and social aspects of vegetable fiber [9]. Also they are using them in trunk liners, instrumental panels, interior roofs, and door panels. Low level of volume fraction provides higher modulus of elastity and good mechanical strength under tensile and flexural loadings but also have values of apparent density, apparent porosity and water absorption $[5,6]$. The addition of $\mathrm{SiC}$ can improve the stiffness by maintaining its low density [8,]. The strength of short fiber composites depends on the type of fiber matrix, fiber orientation, fiber length, fiber concentration and the bonding between the fiber and matrix [10].

\footnotetext{
* Corresponding author: ganeshkalagi082@gmail.com
} 


\subsection{Literature Review}

Mechanical properties of Sisal and Flax fiber reinforced composite are increses by selecting suitable composition of fiber and resin [11].

Sisal fiber gaves good potential as reinforcement in polymer composites. Low density and high specific properits of Sisal fiber, composites taking into account, these filaments may have great applications in the automotive and transportation industry [12].

A experimental investigation on effect of orientation of alkaline treated fiber reinforced composites. The charpy impact strength in the orientation $90^{\circ}$ yielded the maximum impact strength. The orientation $90^{\circ}$ shows the better mechanical properties compare to $0 / 90^{\circ}$ and $45^{\circ}[13]$.

Experimental investigation has been studied on the tensile properties of Sisal and coconut spathe reinforced composites. The distinctive rate of filaments is taken, because of the low density the composites can be viewed as a helpful light weight material [14].

The mechanical properties of Sisal and Flax fiber reinforced composites are incredibly affected by alkalization trématent. Alkaline trématent was found be effective in improvement of tensile and impact properties of natural fibres.

\section{Fabrication}

\subsection{Materials used}

The raw materials used in this work are, Sisal fiber, Flax fiber, SiC Nano powder, Epoxy and Hardener

\subsection{Multiaxial Layers of Flax/Sisal Reinforced with Epoxy and SiC Nano powder}

Flax and Sisal fiber reinforced composites are fabricated by hand layup process into dimensions of length and breadth of $300 \times 200 \mathrm{~mm}$ was used to prepare the specimen. The composite specimen consists of totally 6 multiaxial woven layers of Flax and Sisal at different angles of $+45^{\circ} /-45^{\circ}$ and $0^{\circ} / 90^{\circ}$ as shown in table 2.1 . Specimens were fabricated using hang layup by taking $17 \%$ of Flax , $17 \%$ of Sisal and $6 \%$ of $\mathrm{SiC}$ Nano powder as shown in figure 2 . 1 ..

After composite materials dried completely, unwanted surfaces are to be removed using secondary operations and also cut the materials as per the required ASTM standards.

Table 1. Details of multiaxial layers of Flax and Sisal

\begin{tabular}{|l|l|l|}
\hline Layers & Angle & Fiber Specification \\
\hline Layer 1 & $0^{\circ} / 90^{\circ}$ & Sisal \\
\hline Layer 2 & $+45^{\circ} /-45^{\circ}$ & Flax \\
\hline Layer 3 & $0^{\circ} / 90^{\circ}$ & Sisal \\
\hline Layer 4 & $+45^{\circ} /-45^{\circ}$ & Flax \\
\hline Layer 5 & $0^{\circ} / 90^{\circ}$ & Sisal \\
\hline Layer 6 & $+45^{\circ} /-45^{\circ}$ & Flax \\
\hline
\end{tabular}




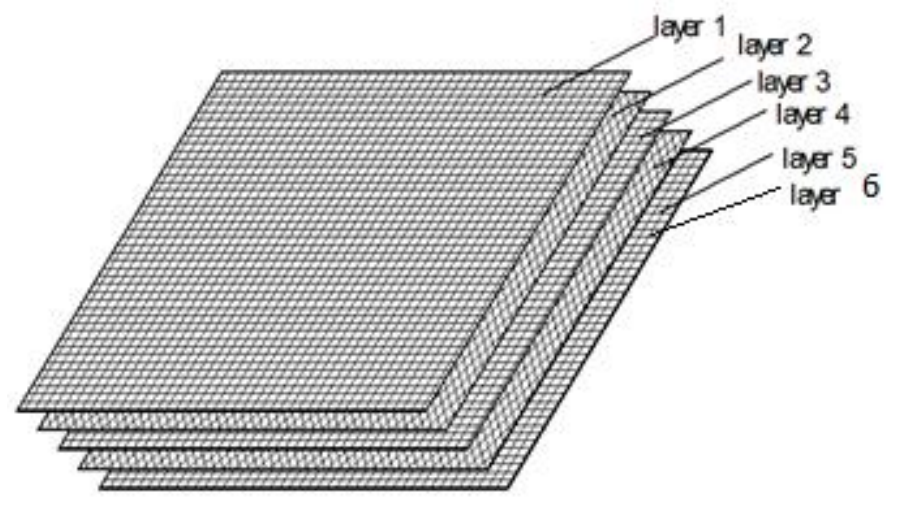

Fig. 1. Multiaxial layers of Flax and Sisal

\subsection{Randomly oriented Chopped Flax/Sisal Reinforced with Epoxy and SiC Nano powder}

Sisal and Flax were cut into a small length of 4 to $6 \mathrm{~mm}$. Dimensions of length and breadth of $300 \times 200 \mathrm{~mm}$ was used to prepare the specimen. These chopped fibers are then fabricated in the ratio of $17 \%$ of Flax, $17 \%$ of Sisal and $6 \%$ of SiC Nano powder.

\section{Mechanical Test}

\subsection{Tensile specimen}

Tensile strength and young's modulus were determined by taking average value of three specimens and ASTM D3039 is used for testing tensile strength of composites. Specimens are fabricated according to ASTM Standard as shown in figure 2.

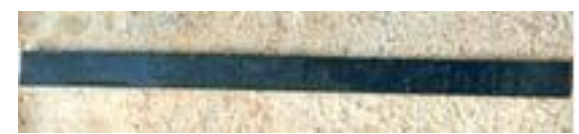

(a)

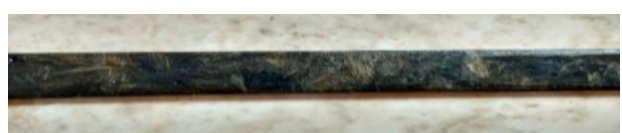

(b)

Fig. 2. Fabricated Specimens for Tensile Test as per ASTM Standards

(a) Woven Flax and Sisal Fiber Reinforced Composite; (b) Randomly oriented Flax and Sisal fiber reinforced composite

\subsection{Impact specimen}

Impact strength of composite material is determined by by taking average value of three specimens carrying followed by ASTM Standards. ASTM E23-15b is used for testing impact strength of composites. Specimens are fabricated according to ASTM Standard as shown in figure 3 . 


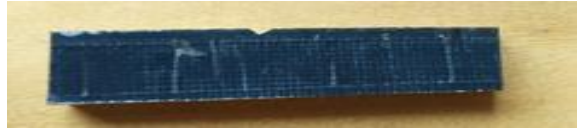

(a)

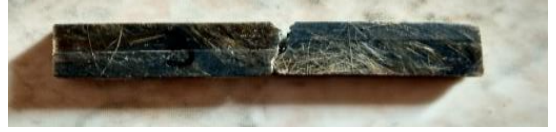

(b)

Figure 3: Fabricated Specimen for Impact Test as per ASTM Standards (a) Woven Flax and Sisal Fiber Reinforced Composite; (b) Randomly oriented Flax and Sisal fiber reinforced

\section{Result and discussion}

\subsection{Tensile test}

It is found that average Tensile strength of multiaxial woven Flax and Sisal fiber reinforced with epoxy and $\mathrm{SiC}$ is $28.13 \mathrm{~N} / \mathrm{mm}^{2}$, and average tensile strength of randomly oriented Flax and Sisal fiber reinforced composites is $13.183 \mathrm{~N} / \mathrm{mm}^{2}$. Tensile strength of composite materials increased by $53.14 \%$ for multiaxial layers of Flax and Sisal are increased.

Strain rate for multiaxial layers of Flax and Sial reinforced composites are $65 \%$ more than that of randomly oriented chopped fiber of Flax and Sisal. But stiffness of randomly oriented chopped fiber of Flax and Sisal reinforced composites are $36.12 \%$ better than multiaxial woven Flax and Sisal fiber reinforced composites.

\subsection{Impact test}

The impact strength of Flax and Multiaxial Woven Sisal fiber reinforced with SiC resulted in higher strength than the chopped fiber reinforced composites. Multiaxial layers of different angled woven fibers are ability to absorb more energy before its failure. Impact strength of composite material is improved by $62.47 \%$ by using multiaxial layers of Flax and Sisal Reinforced with SiC.

\subsection{SEM Analysis}

From the following Figure, Figure. a shows sample's surface topography of multiaxial Woven Flax/Sisal fiber reinforced with $\mathrm{SiC}$ Nano powder and figure.b for Chopped Flax and Sisal fiber reinforced composites.

The topography properties of the fabricated composite surface show the variation in mechanical properties through phase information of the fabricated composites specimens. From the SEM analysis on both composites (Woven and Chopped fiber), It is observed that distribution of fiber and resin is uniform in Woven cloth fiber composite which is resulted in improving impact strenth of composite materil. Where as in case of Chopped fiber composite the fiber and $\mathrm{SiC}$ are randmloy distributed and resulted in poor impact strenth but resukted in more stiffer than woven cloth fiber reinforced comosite. 


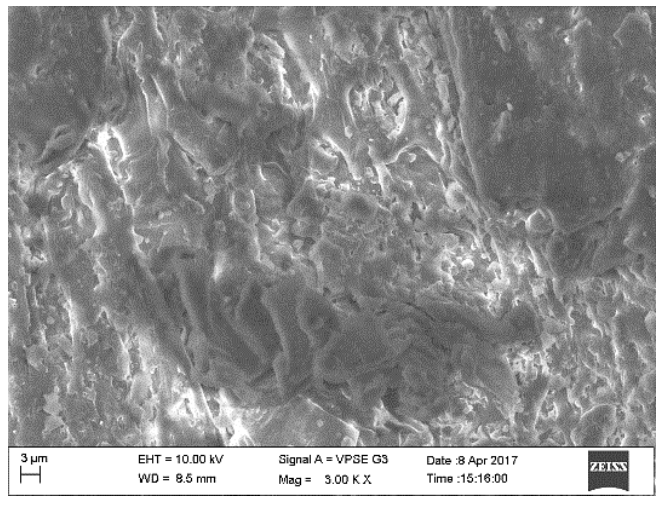

(a)

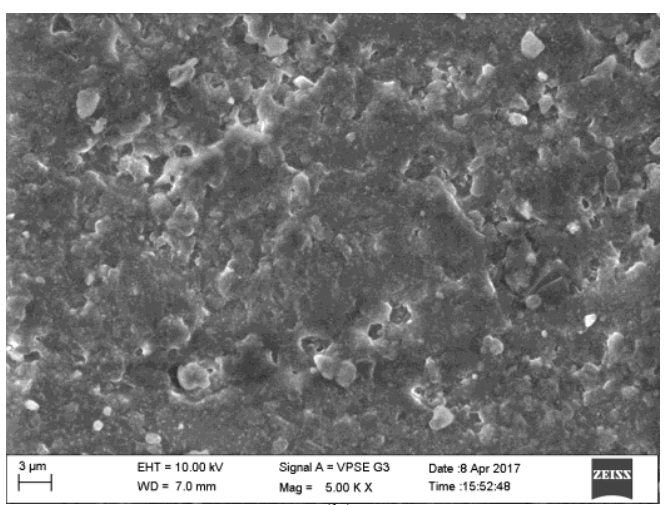

(b)

Fig. 4. (a) SEM images of Woven cloth fiber composites (b) SEM images of Chopped fiber composites

\section{Conclusions}

Natural fibers are superior in mechanical properties and are also bio-degradable. Natural fiber are able to replace glass fiber and carbon for automobile and wind turbine blade applications. But it is very difficult by natural fiber alone. In order to increase the mechanical properties, it is very essential to use multiaxial layers of two or more than two types of natural fiber and Nano particle into it.

In this research, work has been carried out on multiaxial layers of Flax and Sisal fiber reinforced with SiC Nano powder and randomly chopped oriented Flax and Sisal fiber reinforced with $\mathrm{SiC}$ Nanopowder. It is found that uniform distribution of $\mathrm{SiC}$ into Flax/Sisal fiber improved impact strength and tensile strength by more than $50 \%$ than that of randomly oriented chopped fiber. But non uniform distribution of $\mathrm{SiC}$ into randomly oriented chopped fiber improved its stiffness by $36 \%$ more than that of woven cloth fiber reinforced composite.

\section{References}

1. Aakash Sirsshti, Senthiil Dr.P.V , Studies on Material and Mechanical Properties of Natural Fiber Reinforced Composites, The International Journal Of Engineering And Science (IJES), 2014, Volume- 3,Issue-11, pp-18-27.

2. Abdul Gafur, Jahangir A. Khan, Mubarak A. Khan, Rabiul Islam , Mechanical, Thermal and Interfacial Properties of Jute Fabric-Reinforced Polypropylene Composites: Effect of Potassium Dichromate, Materials Sciences and Applications, 2010, pp-350-357.

3. Ahmed F. Hamzah, Mohammed S. Hamzah, Najim A. Saad, Study of Fatigue Behavior of Composite Materials with the Basis of Polyphenylene Sulfide (PPS) Reinforced with Glass Fiber and Carbon, International Journal of Engineering and Technology, 2013, Volume-3 No. 4, pp-467-474.

4. Alagarraja1.K, Dhamodharan.A ,Gopinathan.K, Mathan Raj.R, Ram Kumar.K, Fabrication and Testing of Fiber Reinforced Polymer Composites Material, IOSR Journal of Mechanical and Civil Engineering (IOSR-JMCE), 2014, pp- 27-34. 
5. Alberta Latteri, Gianluca Cicala, Giuseppe Cristaldi, Giuseppe Recca, University of Catania - Department of PhySiCal and Chemical Methodologies for Engineering, Composites Based on Natural Fiber Fabrics, 2010, volume-, pp-317-339.

6. Ashish Chauhan, Balbir Kaith, Priyanka Chauhan, Natural Fiber Reinforced Composite: A Concise Review Article, Chemical Engineering \& Process Technology, 2012, Volume-3, Issue-2, pp-1-2.

7. Ashok Kumar.M, Dasaratha.H Fabrication and Performance of Natural Fibers: Sansevieria cylindrica, waste silk, jute and drumstick vegetable fibers (Moringa Oleifera) reinforced with rubber/polyester composites, International Journal of Fiber and Textile Research, 2011, pp-15-21.

8. Mr. Ganesh R Kalagi. Dr.Rajashekar Patil . Mr.Pradeepa shetty . Mr.Raviprasad . Mr.Sujith kumar . Mr.Vinod ""Mechanical Properties \& SEM Analysis of Flax/Sisal/SiC Nano powder reinforced Hybrid Composites" Journal of Materials Science \& Surface Engineering (JMSS) Vol. 5, Issue 5, 2017, pp 633-636.

9. Debiprasad Gon, Kousik Das, Palash Paul, SubhankarMaity, Jute Composites asWood Substitute, International Journal of Textile Science, 2012, Vol-6, pp-84-93.

10. De Rosa.M, Marra.F, Pulci.G, Santulli.C, Sarasini.F, Tirillo.J, Valente.M, Post-impact mechanical characterization of E-glass/basalt woven fabric interply hybrid laminates, express Polymer Letters, 2011, Vol-5, No.5, pp- 449-459.

11. Mr. Ganesh R Kalagi, Dr. Rajashekar Patil and Mr. Narayan Nayak, "Natural Fiber Reinforced polymer Composite Materials for Wind Turbine Blade Applications", International Journal of Science and Development Research Volume 1, Issue 9, September 2016, pp. 28-37.

12. Kuruvilla Joseph, Romildo Dias Tolêdo Filho, Beena James, Sabu Thomas \& Laura Hecker de Carvalho,a study on a review on Sisal fiber reinforced polymer composites, v.3, n.3, p.367-379, 1999.

13. Kumaresan. M, Sathish. S and Karthi. N, a study on effect of fiber orientation on mechanical properties of Sisal fiber reinforced epoxy composites, Journal of Applied Science and Engineering, Vol. 18, No. 3, pp. 289_294 (2015).

14. Girisha.C, Sanjeevamurthy, Gunti Rangasrinivas, a study on tensile properties of natural fiber reinforced epoxy-hybrid composites, International Journal of Modern Engineering Research (IJMER) Vol.2, Issue.2, Mar-Apr 2012 pp-471-474.

15. Jinchun Zhu, Huijun Zhu, James Njuguna and Hrushikesh Abhyankar, a study on recent development of Flax fibers and their reinforced composites based on different polymeric matrices, materials2013,6,5171-5198;doi:10.3390/ma6115171, ISSN 19961944. 